Article

\title{
An Internet of Things-Based Environmental Quality Management System to Supervise the Indoor Laboratory Conditions
}

\author{
Gonçalo Marques (1) and Rui Pitarma * \\ Unit for Inland Development, Polytechnic Institute of Guarda, Avenida Doutor Francisco Sá Carneiro $\mathrm{N}^{\circ} 50$, \\ 6300-559 Guarda, Portugal; goncalosantosmarques@gmail.com \\ * Correspondence: rpitarma@ipg.pt; Tel.: +351-2712-20111
}

Received: 19 December 2018; Accepted: 24 January 2019; Published: 28 January 2019

check for updates

\begin{abstract}
Indoor air quality (IAQ) is not only a determinant of occupational health but also influences all indoor human behaviours. In most university establishments, laboratories are also used as classrooms. On one hand, indoor environment quality (IEQ) conditions supervision in laboratories is relevant for experimental activities. On the other hand, it is also crucial to provide a healthy and productive workplace for learning activities. The proliferation of cost-effective sensors and microcontrollers along with the Internet of Things (IoT) architectures enhancements, enables the development of automatic solutions to supervise the Laboratory Environmental Conditions (LEC). This paper aims to present a real-time IEQ-laboratory data collection system-based IoT architecture named iAQ Plus $(i A Q+)$. The $i A Q+$ incorporates an integrated Web management system along with a smartphone application to provide a historical analysis of the LEC. The $i A Q+$ collects IAQ index, temperature, relative humidity and barometric pressure. The results obtained are promising, representing a meaningful contribution for IEQ supervision solutions based on IoT. $i A Q+$ supports push notifications to alert people in a timely way for enhanced living environments and occupational health, as well as a work mode feature, so the user can configure setpoints for laboratory mode and schoolroom mode. Using the $i A Q+$, it is possible to provide an integrated management of data information of the spatio-temporal variations of LEC parameters which are particularly significant not only for enhanced living environments but also for laboratory experiments.
\end{abstract}

Keywords: IAQ; enhanced living environments; IEQ; IoT; smart cities; LEC

\section{Introduction}

Indoor environment quality (IEQ) in buildings incorporates indoor air quality (IAQ), acoustics, thermal comfort, and lighting [1]. It is well known that poor IEQ has a negative effect on occupational health, particularly on children and old people.

Poor IAQ is a significant problem which affects particularly the underprivileged people in the world, as they remain most exposed, presenting itself as a critical problem for global health such as tobacco use or the problem of sexually transmitted diseases [2]. The Environmental Protection Agency (EPA) is responsible for indoor and outdoor air quality supervision in the United States. The EPA assessment recognises that IAQ pollutants concentration can be up to 100 times greater when compared with the outdoor pollutants concentration levels and established poor air quality, which are in the top five environmental risks to global health [3].

Indoor living environments include several types of spaces and workplaces such as offices, hospitals, public service centres, schools, libraries, leisure spaces and also the cabins of vehicles [4]. In particular, schools are an essential place to monitor. Typically, the large number of occupants, the time spent indoors, 
and the higher density of occupants justifies the need to develop automatic supervision systems to provide a healthful and productive workplace for students, teachers and school staff [5].

Buildings are responsible for $40 \%$ of the global energy consumption and $30 \%$ of the $\mathrm{CO}_{2}$ emissions. Thermal comfort assurance is related to a substantial percentage of the referred energy consumption. The adoption of personalised conditioning systems is apparently a reliable approach to improve user acceptability with the environment thermal conditions since thermal comfort is a complicated subject with several interrelated aspects that need to be understood [6].

Currently, IEQ in buildings is based on random sampling. However, these procedures are only providing information relating to a specific sampling and are devoid of details of spatio-temporal variations, which are particularly relevant in laboratory tests such as thermography experiments.

The fundamental concept of the Internet of Things (IoT) is the pervasive presence of several types of devices with communication and collaboration skills between them to reach a mutual purpose [7]. The IoT will not only improve everyday life behaviours and activities in different areas such as smart homes, assisted living environments and smart-health, but also in present innovative data and computational resources to develop novel software solutions [8]. One of the fields where the IoT plays a significant role is IAQ monitoring [9]. The rapid increasing of Information and Communication Technologies (ICTs) and IoT proliferation offer significant opportunities in the development of healthcare information systems. However, challenges still exist in achieving safety, security and privacy for healthcare applications $[10,11]$.

Ambient Assisted Living (AAL) is a research area which studies the conceptualisation of an ecosystem of diverse kinds of sensors, computers, mobile gadgets, wireless networks and software development for enhanced personal healthcare supervision and telemedicine solutions [12]. At 2050, a significant proliferation of diseases will lead to high healthcare costs, lack of caregivers, dependency and notable social impact, because $20 \%$ of the world population will be aged 60 or over [13]. Most people (87\%) prefer to stay in their houses and pay a significant charge for nursing care [14]. However, there are numerous difficulties in AAL solutions conceptualisation and development such as data structure, user-interface, human-computer communication, ergonomics, usability and accessibility [15]. Furthermore, the AAL solutions adopted by the aged population is influenced by social and ethical obstacles. Therefore, privacy and confidentiality are fundamental to AAL solutions' development. Actually, technology should not substitute human care but must be seen as a useful supplement. IoT and AAL research can be conducted side by side in order to present multiple advantages to various healthcare activities such as not only the identification, authentication and tracking of objects and patients but also in automated data acquisition, consulting and storage [16].

The "smart city" approach has recently been proposed as an important method to include current urban production circumstances in a mutual framework especially to focus the ICTs influence in the last 20 years on city performance [17]. The smart city concept is associated with a recent approach to decrease the obstacles caused by the growth of urban population and rapid urbanisation [18]. The interoperability of heterogeneous technologies and devices is a significant challenge in smart cities; IoT can offer the interoperability needed to create unified urban-scale ICT [19].

IoT incorporates notable features to develop innovative real-life solutions and services for smart cities [20], particularly for environmental quality supervision. The smart home is an indispensable element in smart cities [21]. In the future, smart homes should incorporate IoT wearable gadgets managed by smartphone applications and powered by miniaturised built-in sensors [22]. Smart homes follow the AAL paradigm, which enables access to health-care services for patients and medical staff as well as other AAL applications [23]. The use of the paradigm of cognitive dynamic systems associated with IoT architectures in intelligent houses is proposed by Reference [24]. According to this study, the smart home can benefit from several building blocks of the cognitive dynamic system (CDS) along with the incorporation of IoT.

This paper aims to present an environmental quality solution based on IoT to supervise Laboratory Environmental Conditions (LEC) named $i A Q+$. This low-cost wireless solution for 
IEQ supervision incorporates mobile computing technologies for data consulting, easy installation, significant notifications for enhanced living conditions, and laboratory activities.

\section{Related Work}

Several studies have shown the IAQ importance in schoolrooms. The IAQ of public primary Portuguese schools was analysed in 73 primary classrooms in Porto [25]. This study indicates that IAQ deficiencies can persist in classrooms with pollutant sources and defective ventilation. Therefore, pollutant source regulation procedures are the most effective methods for the prevention of unfavourable health impacts on children in scholar institutions. The effectiveness of manual airing strategies on the IAQ of naturally ventilated Italian schools was presented by Reference [26]. A study conducted in New York State primary and secondary schools organised by 501 teachers concluded that many classroom characteristics are probably associated with bad IAQ and over $40 \%$ of the teachers described a minimum of one health symptom associated with the building construction [27]. A review of the association between IAQ and its consequences on respiratory wellbeing in Malaysian students was proposed by Reference [28]. Despite the relatively small-scale epidemiologic evidence, Malaysian research proposes effective and relatively consistent evidence among IAQ and children's respiratory health. Another study that characterises the levels of several indoor air contaminants at scholar institutions in Hong Kong, correlates the calculated concentrations with proper standards, and recommend methods to decrease the exposure of students to unwanted pollutants was proposed by Reference [29].

On the one hand, in most university establishments, laboratories have a large number of polluting sources. On the other side, these spaces are very often used as classrooms. Therefore, university laboratories need to be monitored for two purposes: as a classroom (IAQ parameters, including thermal comfort) and/or to ensure different conditions for sampling and performing experiments with reliable quality and data. Most people consider thermal comfort with higher importance when compared with visual and acoustic comfort and IAQ [30]. The comfort temperature might be as low as $17^{\circ} \mathrm{C}$ and as high as $30^{\circ} \mathrm{C}$. Thermal comfort is influenced by several factors such as air temperature, radiant temperature, air velocity, humidity, clothing insulation and metabolic heat. The first four factors can be measured and the last two are personalised factors [31]. Although, for laboratory experiments, the recommendation is $23^{\circ} \mathrm{C}\left( \pm 5^{\circ} \mathrm{C}\right)$ and $<70 \% \mathrm{RH}$ for temperature and relative humidity respectively. A study on the thermal comfort in a Portuguese school was presented by Reference [32].

Multiple studies on environmental quality supervision are accessible in the literature. This section presents several prominent low-cost solutions which include not only open-source but also mobile computing technologies.

A wireless sensor network (WSN) low-cost solution for proper greenhouse pepper cultivation which incorporates proper supervision methods such as remote administration for drip irrigation and equipment control was proposed by Reference [33].

A real-time WSN architecture for environmental supervision which provides acoustic levels, temperature, relative humidity and particulate matter concentration data collection for smart cities was proposed by Reference [34].

A WSN approach for temperature distribution supervision in large-scale indoor environments was proposed by Reference [35]. This methodology aims to enhance the quality of the data transmitted by wireless signals, classify the temperature distribution model and improve the allocation of supplied air measure flow levels to various supply air terminals which fulfill the area taking into account the temperature distribution model.

Numerous IoT solutions for IAQ supervision which merge open-source technologies not only for processing and data transmission and sensors for data collection but also to provide data consulting from distinct areas at the same time using Web and smartphone applications in real time are proposed by References [36-43]. 
The $i A Q+$ solution proposes a valuable instrument for enhanced living environments in smart cities. The advantages for well-being, comfort and productivity of healthy IAQ levels can be enhanced by reducing the pollutant concentration when the ventilation is still unchanged [44]. Consequently, the authors propose a wireless system which incorporates an ESP8266 module which performs the IEEE $802.11 \mathrm{~b} / \mathrm{g} / \mathrm{n}$ networking protocol. The ESP8266 support built-in Wi-Fi technology, therefore, this module is used not only as a processing unit but also for data transmission. For data consulting, this solution uses a smartphone application developed using SWIFT language for the iOS operating system (Figure 1).

Taking into account the IAQ influence on health, the development of a low-cost, open-source supervision system is a trending idea. Therefore, several monitoring solutions have been created [45-52]. Regarding the quality and important contribution of the referred solutions, a review of these studies is presented in Table 1.

Table 1. A summary comparison of real-time IAQ monitoring studies.

\begin{tabular}{|c|c|c|c|c|c|c|c|c|c|}
\hline Authors & MCU & Sensors & Architecture & Low Cost & Open-Source & Connectivity & $\begin{array}{l}\text { Data } \\
\text { Access }\end{array}$ & $\begin{array}{c}\text { Easy } \\
\text { Installation }\end{array}$ & Notifications \\
\hline $\begin{array}{l}\text { P. Srivatsa and A. } \\
\text { Pandhare [45] }\end{array}$ & $\begin{array}{l}\text { Raspberry } \\
\text { Pi }\end{array}$ & $\mathrm{CO}_{2}$ & WSN/IoT & $\sqrt{ }$ & $\sqrt{ }$ & Wi-Fi & Web & $x$ & $\times$ \\
\hline $\begin{array}{l}\text { F. Salamone et al. } \\
\text { [46] }\end{array}$ & $\begin{array}{l}\text { Arduino } \\
\text { UNO }\end{array}$ & $\mathrm{CO}_{2}$ & WSN & $\sqrt{ }$ & $\sqrt{ }$ & ZigBee & $\times$ & $x$ & $\times$ \\
\hline $\begin{array}{l}\text { S. Bhattacharya } \\
\text { et al. [47] }\end{array}$ & Waspmote & $\begin{array}{c}\mathrm{CO}, \mathrm{CO}_{2}, \mathrm{PM}, \\
\text { Temperature, } \\
\text { Relative Humidity }\end{array}$ & WSN & $x$ & $\sqrt{ }$ & ZigBee & Desktop & $x$ & $x$ \\
\hline $\begin{array}{l}\text { F. Salamone et al. } \\
\text { [48] }\end{array}$ & $\begin{array}{l}\text { Arduino } \\
\text { UNO }\end{array}$ & $\begin{array}{c}\text { Temperature, } \\
\text { Relative Humidity, } \\
\mathrm{CO}_{2} \text {, Ligth, Air } \\
\text { velocity }\end{array}$ & IoT & $\sqrt{ }$ & $\sqrt{ }$ & $\begin{array}{l}\text { ZigBee / } \\
\text { BLE }\end{array}$ & Mobile & $x$ & $\times$ \\
\hline $\begin{array}{l}\text { Wang, S.K } \\
\text { et al. [49] }\end{array}$ & Arduino & $\begin{array}{c}\text { Temperature, } \\
\text { Relative Humidity, } \\
\mathrm{CO}_{2}\end{array}$ & WSN & $\sqrt{ }$ & $\sqrt{ }$ & ZigBee & Desktop & $x$ & $\times$ \\
\hline $\begin{array}{l}\text { Jen-Hao Liu } \\
\text { et al. [50] }\end{array}$ & $\begin{array}{c}\text { TI } \\
\text { MSP430 }\end{array}$ & $\begin{array}{l}\mathrm{CO}, \text { Temperature, } \\
\text { Relative Humidity }\end{array}$ & WSN & $\sqrt{ }$ & $\sqrt{ }$ & ZigBee & $x$ & $x$ & $\times$ \\
\hline $\begin{array}{l}\text { J.Kang and K. } \\
\text { Hwang [51] }\end{array}$ & $\begin{array}{c}\text { TI } \\
\text { MSP430 }\end{array}$ & $\begin{array}{l}\text { CO, Temperature, } \\
\text { Relative Humidity, } \\
\text { VOC, PM }\end{array}$ & IoT & $\sqrt{ }$ & $x$ & ZigBee & $\times$ & $\times$ & $\times$ \\
\hline $\begin{array}{l}\text { Benammar M. et } \\
\text { al [52] }\end{array}$ & $\begin{array}{l}\text { Raspberry } \\
\text { Pi }\end{array}$ & $\begin{array}{c}\mathrm{CO}_{2}, \mathrm{CO}, \mathrm{SO}_{2} \\
\mathrm{NO}_{2}, \mathrm{O}_{3}, \mathrm{Cl}_{2}, \mathrm{CO}, \\
\text { Temperature, } \\
\text { Relative Humidity }\end{array}$ & IoT/WSN & $\sqrt{ }$ & $\times$ & \multicolumn{2}{|c|}{ ZigBee/Ethernet $\times$} & $x$ & $\times$ \\
\hline
\end{tabular}
MCU: microcontroller; $\sqrt{ }:$ apply; $\times$ : not apply.

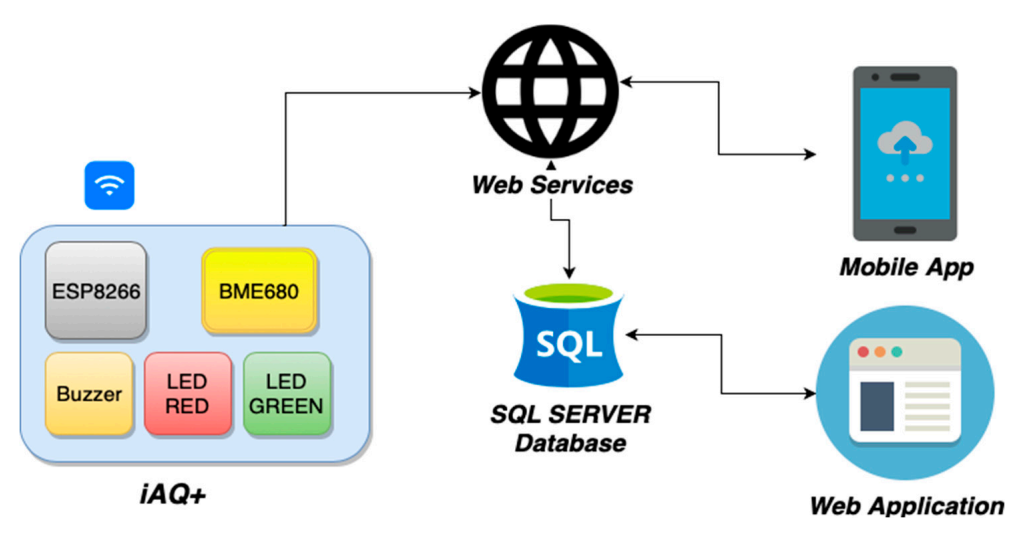

Figure 1. $i A Q+$ architecture.

\section{Proposed $i A Q+$ Management System}

Considering the importance of developing a cost-effective system, only the Bosch BME680 sensor was chosen. This sensor was selected since it is an integrated environmental sensor produced particularly for portable applications and wearables where dimension and low power consumption 
are essential requirements. This sensor provides temperature, relative humidity, barometric pressure and qualitative air quality, the main parameters that should be supervised for both school and laboratory scenarios. The proposed system is composed of a hardware prototype for environmental data acquisition and a Web portal and mobile application compatible for data access (Figure 1). The $i A Q+$ is based on open-source technologies and is a totality Wi-Fi solution with various benefits when related to current solutions, such as its modularity, scalability, low-cost, real-time notifications and easy installation. The data collected is stored in a SQL Server database management system and a smartphone application or a Web portal can be used for data consulting. The $i A Q+$ incorporates the ESP8266 microcontroller with built-in Wi-Fi communication technology and has been tested in the context of infrared thermography experiments.

Taking into consideration the SQL Server native .NET framework integration feature, this database management system was chosen. Furthermore, the SQL Server incorporates several advantages such as data-recovery features, professional management utilities and built-in data compression and data encryption features. The SQL Server supports easy administration and audit functionalities for enhanced data management.

\section{Laboratory Environmental Conditions}

LEC supervision is critical from a quality perspective to provide a consistent and regulated state of control for equipment and samples for proper lab activities. LEC is influenced by the building envelope, thermal loads, obstructions and buildings climatisation system, which can produce air flow patterns of hot and cold spots. In some cases, these hot and cold spots can produce environmental conditions variations during experiment activities which lead to unwanted effects on samples as well as manipulation of the testing equipment's samples. Therefore, the LEC must be monitored in real-time not only to assure proper regulation and maintenance of indoor conditions but also to correlate the collected samples with these conditions.

On the one hand, the laboratory activities must be monitored and stored to ensure that they are stable when the test is conducted and at the data collection moment as they influence the quality of the results. LEC has a significant influence on test results and on the precision and reliability of testing records that remain concerned with environmental parameters. On the other hand, monitored results must be saved in the laboratory information management system that should provide the following requisites: 1) must incorporate authentication and access control for data safety; 2) must incorporate data recovery and data adulteration protection methods; 3 ) must be manipulated in an environment that satisfies the provider or laboratory specs or, in the situation of non-computerized methods, provides conditions which preserve the precision of manual reporting and transcription; 4) must be managed to guarantee the information integrity; and 5) must implement reporting system crashes support to allow prompt corrective operations.

In general, temperature, humidity and barometric pressure are assumed as the main conditions to be monitored for enhanced laboratory environments. The recommendation for LEC is $23^{\circ} \mathrm{C}\left( \pm 5^{\circ} \mathrm{C}\right)$ and $<70 \% \mathrm{RH}$ for temperature and relative humidity respectively. For temperature data collection, the measurements must be made with calibrated sensors that must be placed far from the equipment under analysis to anticipate every heating consequence which can lead to inaccurate ambient samples. Regarding the humidity measurements, the data collected must be done at the same altitude from the ground as the equipment under test and, preferably, in a similar place if possible. The barometric levels can be consulted from local airports. However, for critical laboratory experiences, barometer sensors are required and must be placed in the laboratory to detect indoor building environmental limitations and barometric fluctuations.

IAQ has a significant influence on LEC [53-56]. On the one hand, IAQ should be supervised in order to provide a healthy and productive workplace for the researchers. On the other hand, IAQ should be monitored to minimise the impact the laboratory experiments' samples. For instance, 
IQ is extremely significant in the clinical embryology laboratory activities and is recognised as a significant parameter which influences in vitro fertilisation (IVF) success levels [57].

\section{Materials and Methods}

Taking into account, not only the necessity to keep a healthful and productive workplace for the students, teachers and the school staff, but also to provide a consistent and regulated state of control for laboratory activities, the $i A Q+$ solution has been created by the authors. The $i A Q+$ solution provides a low-cost and reliable method for IAQ supervision which incorporates easy configuration and easy installation features. This system is a low-cost, reliable system that can be easily configured and installed by the average user without supporting the cost of an installation done by certified professionals.

The main objective is to provide proper supervision of the LEC, such as air temperature, humidity and barometric pressure and a qualitative air quality index. Therefore, the authors selected a cost-effective BOSCH BME680 sensor, a four-in-one multi-functional microelectromechanical system (MEMS) environmental sensor which integrates a Volatile Organic Compounds (VOC) sensor, temperature sensor, humidity sensor and barometer. The DFRobot Gravity BME680 environmental sensor was used as it provides a Gravity I2C connector, is plug \& play and is easy to connect.

The $i A Q+$ is based on a microcontroller with built-in Wi-Fi compatibility, a FireBeetle ESP8266 (DFRobot). Figure 2 presents the hardware prototype developed by the authors. In this section, the hardware and software development materials and methods will be discussed.

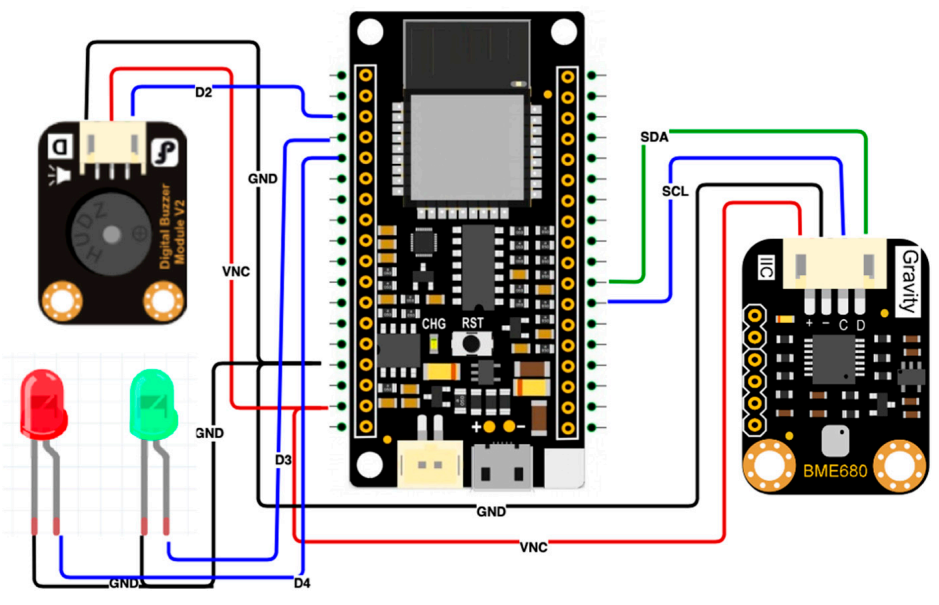

Figure 2. $i A Q+$ prototype.

A brief introduction of each component used is shown below.

- FireBeetle ESP8266 is 32-bit Tensilica L106 microcontroller module which supports IEEE802.11 $\mathrm{b} / \mathrm{g} / \mathrm{n} \mathrm{WiFi}(2.4 \mathrm{GHz} 2.5 \mathrm{GHz})$. This module support one 10-bit analogue input, 10 digital inputs which incorporate multiple interfaces such as SPI, I2C, IR, and I2S. The clock speed is $80 \mathrm{MHz}$ and can reach a maximum 160MHz; in addition, it includes a 50KB SRAM and 16MB flash memory. It supports a low-power-consumption mode of $46 \mathrm{uA}$ and the operating voltage is $3.3 \mathrm{~V}$.

- DFRobot Gravity BME680 is an I2C environmental VOC sensor, temperature sensor, humidity sensor and barometer. It supports an input voltage of 3.3-5.0 V; the operating current consumption is $5 \mathrm{~mA}$ without air quality sensing and $25 \mathrm{~mA}$ with air quality features. This sensor module size is $30 \times 22 \mathrm{~mm} / 1.18 \times 0.87$ inches. The temperature range is from $-40{ }^{\circ} \mathrm{C}$ to $+85^{\circ} \mathrm{C}$ with a precision of $\pm 1.0^{\circ} \mathrm{C}\left(0-65^{\circ} \mathrm{C}\right)$. The humidity range is from 0 to $100 \% \mathrm{r}$.H with a precision of a $\pm 3 \%$ r.H. $\left(20-80 \%\right.$ r.H., $\left.25^{\circ} \mathrm{C}\right)$. The atmospheric pressure measurement range is from 300 to $1100 \mathrm{hPa}$ with a precision of $\pm 0.6 \mathrm{hPa}\left(300-1100 \mathrm{hPa}, 0-65^{\circ} \mathrm{C}\right)$.

- DFRobot Buzzer Module is a buzzer module that supports an input voltage of 3.3-5.0 V. 
- $\quad 5 \mathrm{~V}$ Green LED-a $5 \mathrm{~V}$ green LED is used to notify the end-user of a good IEQ conditions.

- $\quad 5 V$ Red LED-a 5 V red LED is used to notify the end-user of poor IEQ conditions.

The BME680 sensor calculates the sum of VOCs in the surrounding air to provide qualitative air quality data. This sensor incorporates a background auto-calibration feature in order to provide reliable IAQ qualitative data. This process regards the recent measurement records to guarantee that IAQ index $\sim 25$ matches to typical good air and IAQ index $\sim 250$ states for typical polluted air. The sensor output resistance value varies according to VOCs concentrations, the higher the concentration of reducing VOCs, the lower the resistance and vice versa. The IAQ qualitative range is from 0 to 500 (the larger, the worse). Table 2 illustrates the IAQ qualitative index meaning of the selected sensor.

Table 2. BME680 qualitative IAQ index meaning.

\begin{tabular}{cc}
\hline IAQ index & Air Quality \\
\hline $0-50$ & Good air quality \\
$51-100$ & Normal air quality \\
$101-150$ & Little poor air quality \\
$151-300$ & Poor air quality \\
$201-300$ & Bad air quality \\
$301-500$ & Very bad air quality \\
\hline
\end{tabular}

The mobile application, designated as $i A Q+$ Mobile, was created using SWIFT programming language in XCode IDE (Integrated Development Environment), and the minimum requirement is the iOS 12. The $i A Q+M o b i l e$ incorporates significant highlights as it allows not only real-time data access of the last temperature, humidity, air pressure and qualitative IAQ index information but also to receive real-time warnings to notify the occupants when the IEQ has severe deficiencies (Figure 3). The smartphone application also allows viewing the collected data in chart form.

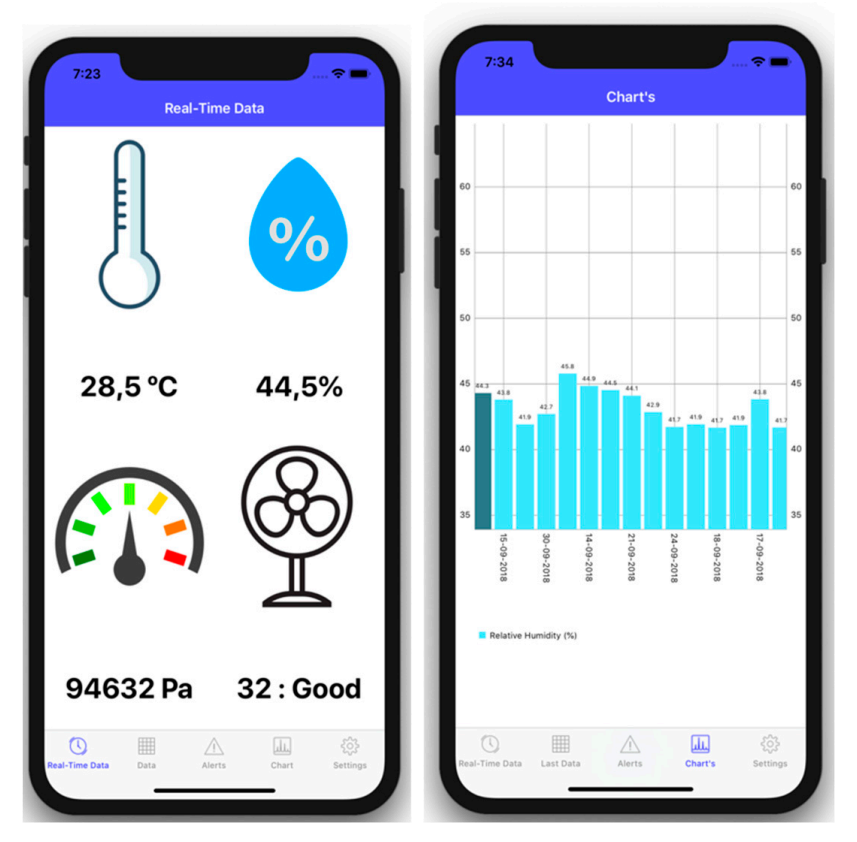

Figure 3. iAQ+Mobile.

The $i A Q+$ was developed by the authors to be a centralised supervision solution. Therefore, the Web application, $i A Q+W e b$, was built in ASP.NET C\# using the Visual Studio IDE. Using the $i A Q+W e b$, the build manager can consult the IEQ data in real time. This Web portal saves the IEQ conditions history for future analysis (Figure 4). 


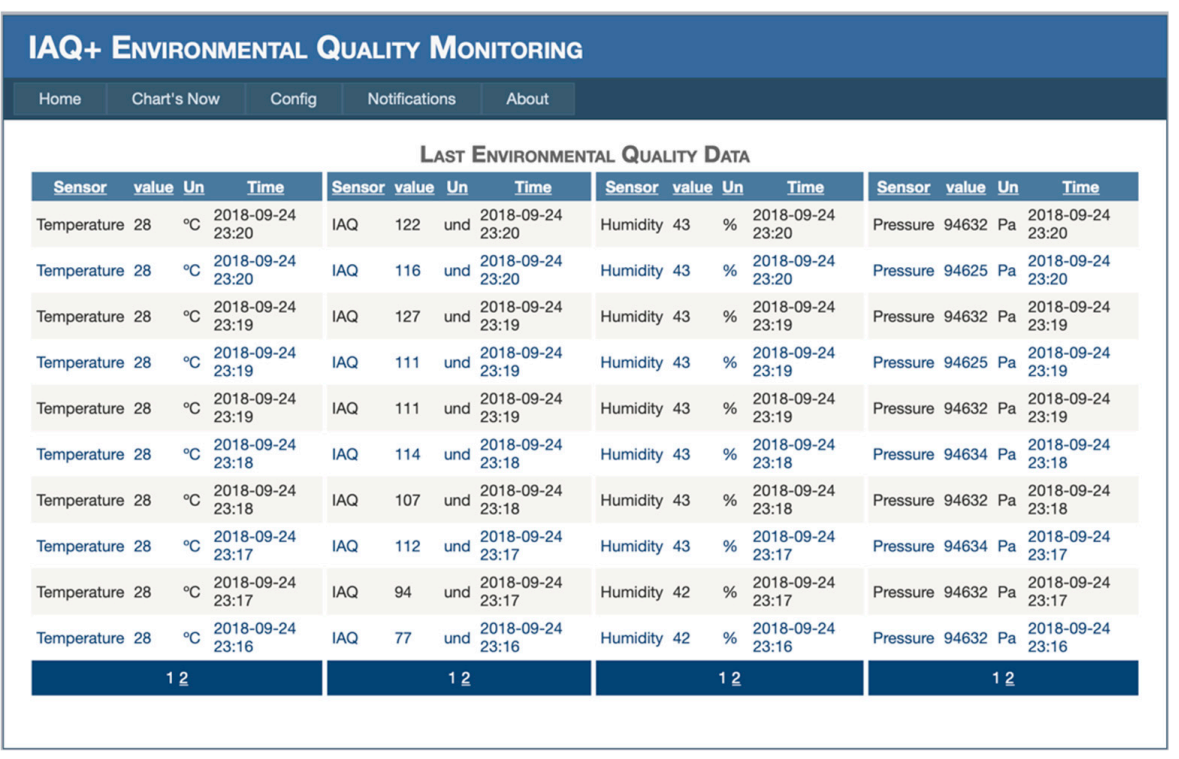

Figure 4. $i A Q+W e b$.

The $i A Q+W e b$ allows historical data export for enhanced reporting and analysis. The Web portal supports hourly, daily and monthly charts and tables of the monitored data for enhanced building management and audits.

To support the two main activities in the university laboratories, the laboratory experiments and teaching activities, the $i A Q+$ software (Web and smartphone) supports two functional modes, the laboratory mode and the schoolroom mode. The $i A Q+$ software allows the user to configure setpoints for both modes and the laboratory manager can change the status mode using the Web or the smartphone app. The smartphone app is an agile and effective way to change the status. However, the software allows the end-user to schedule the working modes (Figure 5).

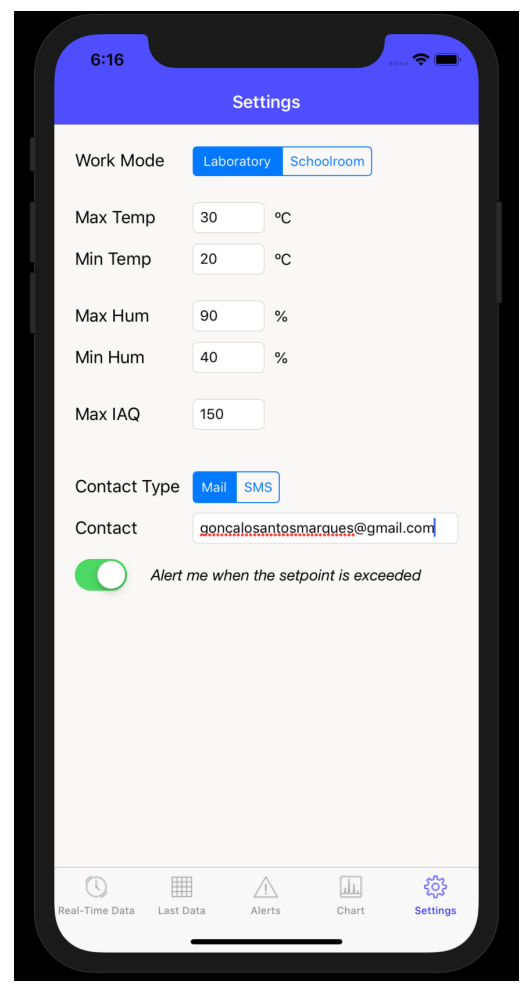

Figure 5. $i A Q+$ Mobile Settings. 


\section{Results and Discussion}

In Portugal, the majority of indoor environments have natural ventilation. The nature of dwelling, construction, heating and ventilation assumes an important influence on the air permeability variations. It is expected that over $66 \%$ of business/services constructions which support natural ventilation mechanisms are notably airtight, and the other 33\% have a tendency to be leakier.

For testing purposes, one laboratory of a Portuguese university were on-site supervised using one $i A Q+$ prototype. Figure 6a presents the experiment conducted by the authors of LEC supervision of thermography activities. As in most laboratories, the supervised space incorporates natural ventilation and does not have dedicated ventilation slots on the facades. The indoor air is reheated and recirculated through a couple of standard air-water fan-coils of the heating system, and the air exchange is performed through infiltrations and by opening windows manually. The outdoor air is employed to afford ventilation, to reduce the temperature or when the occupants detect the severe or disturbing odour; therefore, the IAQ is frequently deficient.

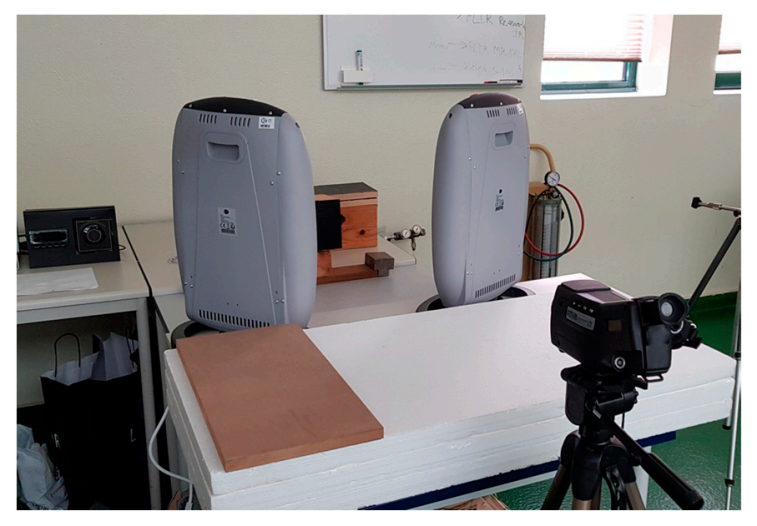

(a)

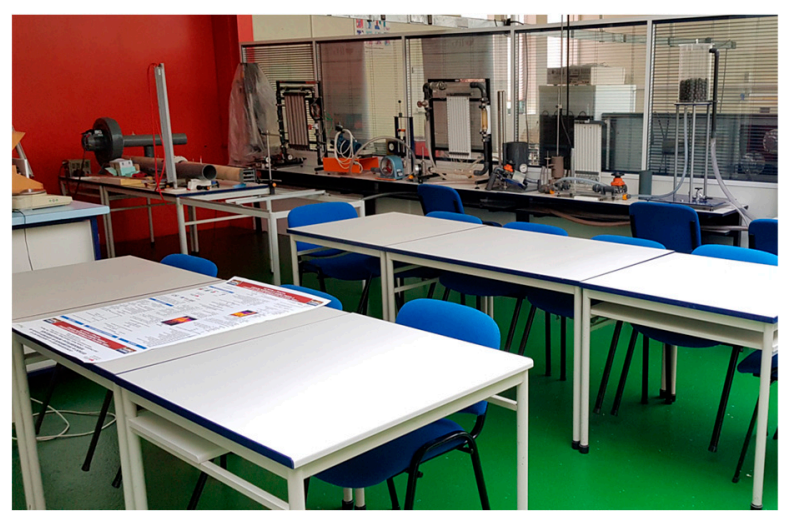

(b)

Figure 6. Laboratory layout: (a) experiments research area (e.g. thermography experiments supported by $i A Q+)$; (b) classroom learning space (teaching support).

The $i A Q+$ was powered by the power grid using a 230V-5V AC-DC 2A power supply. The LEC exposure data were collected in thermography experiments which showed that indoor conditions can be different from the recommended values and can affect the integrity of the collected data.

The tests conducted show the system capability not only to keep a healthful and productive workplace for the students, teachers and the school staff but also to provide a consistent and regulated state of control for laboratory activities. Figure $6 \mathrm{~b}$ represents the laboratory space used as a schoolroom.

Figure 7 presents a sample of the graphics of the results achieved in the tests conducted. It should be noted that the graphs displayed the results obtained in the monitored rooms with induced simulations using tobacco smoke.

On one hand, monitoring environmental conditions and maintaining laboratory temperature and humidity requirements is extremely important for high-quality experimental activities. On the other hand, supervising IEQ is significant in creating a healthy and productive workplace for learning and teaching. Using the smartphone application, the user can carry all the monitored data in his pocket.

This solution not only supports alerts and setpoints configuration for real-time notifications via e-mail, SMS and push notifications but also provides an integrated dashboard for the monitored real-time collected data. Quite apart from this, the $i A Q+$ incorporates a built-in visual and audio alarm, two LED's and a buzzer respectively. When the configurated setpoints are met, the correspondent LED is triggered, green to inform the good IEQ status and red to notify the poor IEQ status along with the buzzer activation. In the last case, the buzzer will ring for 30 seconds with the aim to notify the occupants to act in real-time to enhance the indoor conditions. 


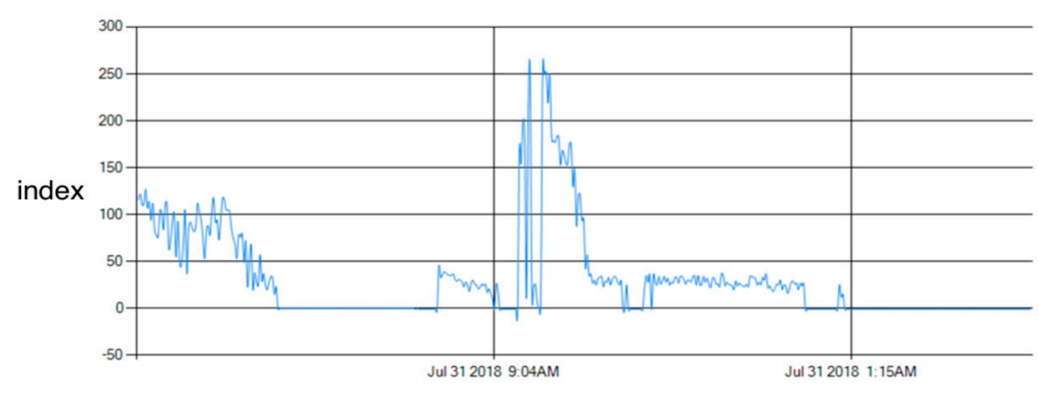

(a)

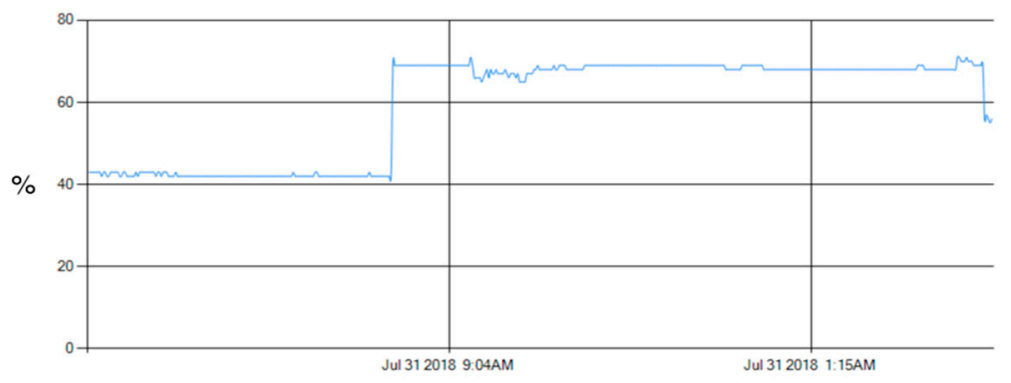

(b)

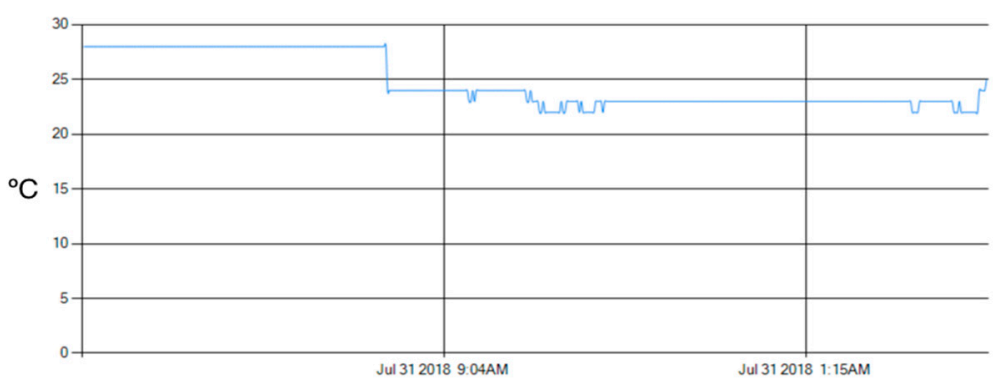

(c)

Figure 7. Results of IAQ index, air temperature and relative humidity obtained in the experiments conducted in a real laboratory environment: (a) IAQ index; (b) relative humidity $(\%)$; (c) air temperature $\left({ }^{\circ} \mathrm{C}\right)$.

The data collected by the system is analysed before being inserted into the database. If the data exceeds the parameterised limits, the user is notified and an email or SMS is triggered (Figure 8).

The SMS notification is performed using Twilio, a cloud communication platform, as a service. This service makes it possible to programmatically send an SMS and other communication functions using its Web service APIs. The push notifications are performed using the Firebase Cloud Messaging that is a cross-platform solution for messages and notifications for Android, iOS and Web applications.

The real-time alerts promote behaviour changes. In fact, these messages alert the user to act in real-time to perform actions to increase IAQ. On the other hand, with this real-time feature, the building manager can understand when the recurrent unhealthy cases are detected and implement new adjustments to prevent them. Consecutively, $i A Q+$ provides the requirements to act in real-time for enhanced living environments and laboratory conditions. The alert indicators architecture is shown in Figure 9. 


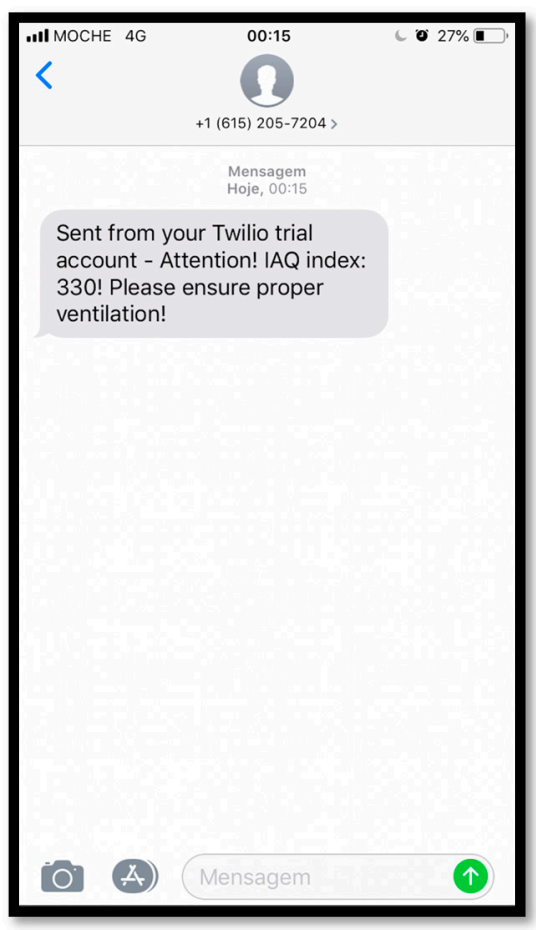

(a)

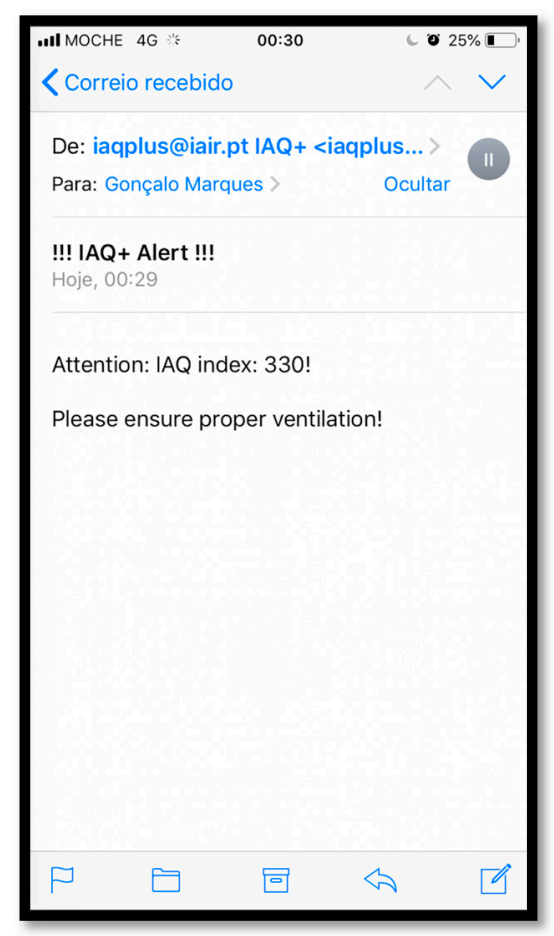

(b)

Figure 8. Examples of SMS (a) and E-mail (b) notifications.

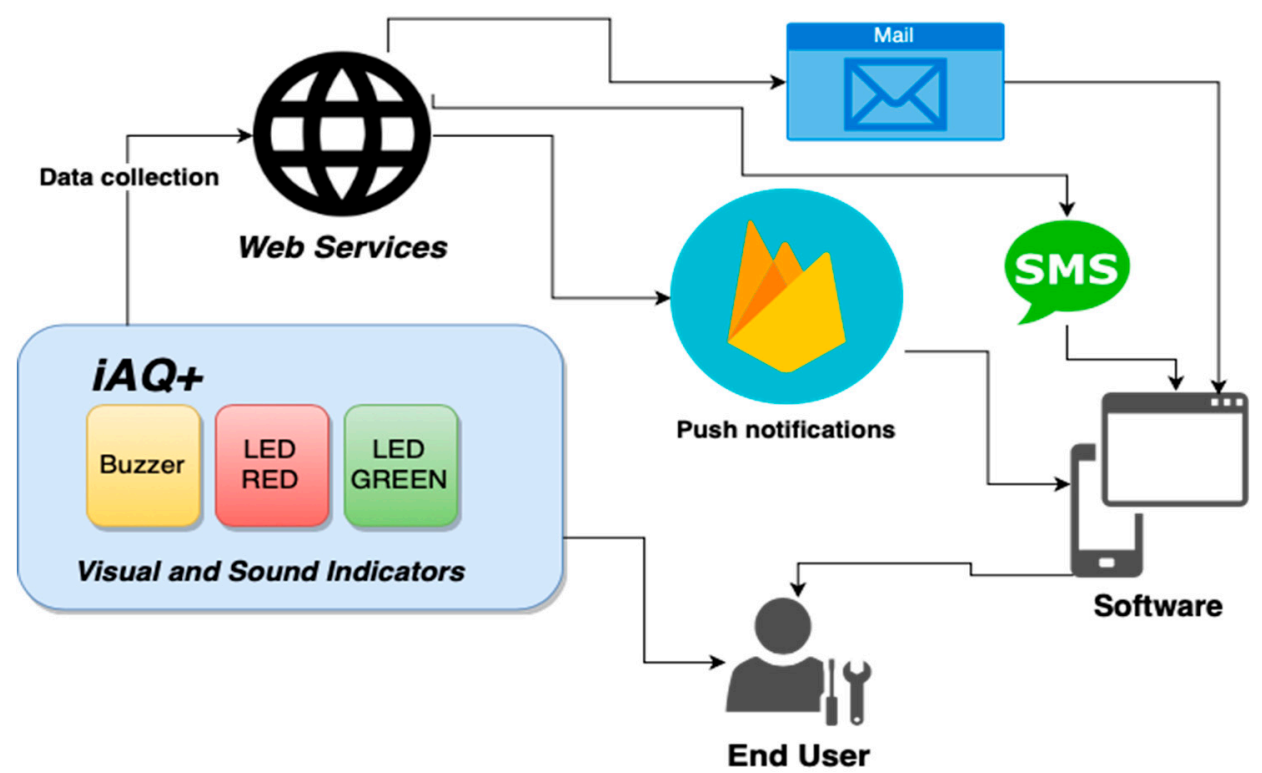

Figure 9. Alerts indicators architecture.

Firstly, $i A Q+$ can help in the maintenance of LEC by providing an integrated management system that supports daily records of historical behaviours and variations as well as remote notifications when the configurated setpoints are met. Secondly, this system can not only be used by the building manager to detect unhealthy situations in real-time but also as a decision-making tool to address behavioural changes to promote IEQ for enhanced productive environments.

From a quality point of view, supervising the laboratory environment is crucial to achieving a continuous LEC in the laboratory activities. Irregular maintenance of LEC can lead to unwanted effects 
to samples as well as to laboratory equipment's ability to produce stable results. The $i A Q+$ allows the user to store the historical data of the LEC; therefore, it is possible to check the integrity of the collected data and perform data analysis and comparison taking into account the indoor conditions.

Through charts visualisation of IEQ conditions, the application provides a better acknowledgement of the supervised data when compared to the numeric table format. Consequently, the proposed solution is a significant decision-making tool to plan interventions in order to promote a healthful and productive living environment but also for IEQ analysis.

The $i A Q+$ incorporates a wireless connection interface for Internet access along with an easy Wi-Fi network configuration. The $i A Q+$ should be connected to a Wi-Fi hotspot for data transmission and to store the network credentials on the flash memory after successful connection. At system start-up, the $i A Q+$ searches for a stored Wi-Fi network to connect to. However, if there no saved Wi-Fi networks available, the system will turn to hotspot mode and create a Wi-Fi network with an SSID "iAQ+". At this stage, the user must connect to the referred hotspot in order to configure the credentials of the Wi-Fi network to which the system will be connected (Figure 10).

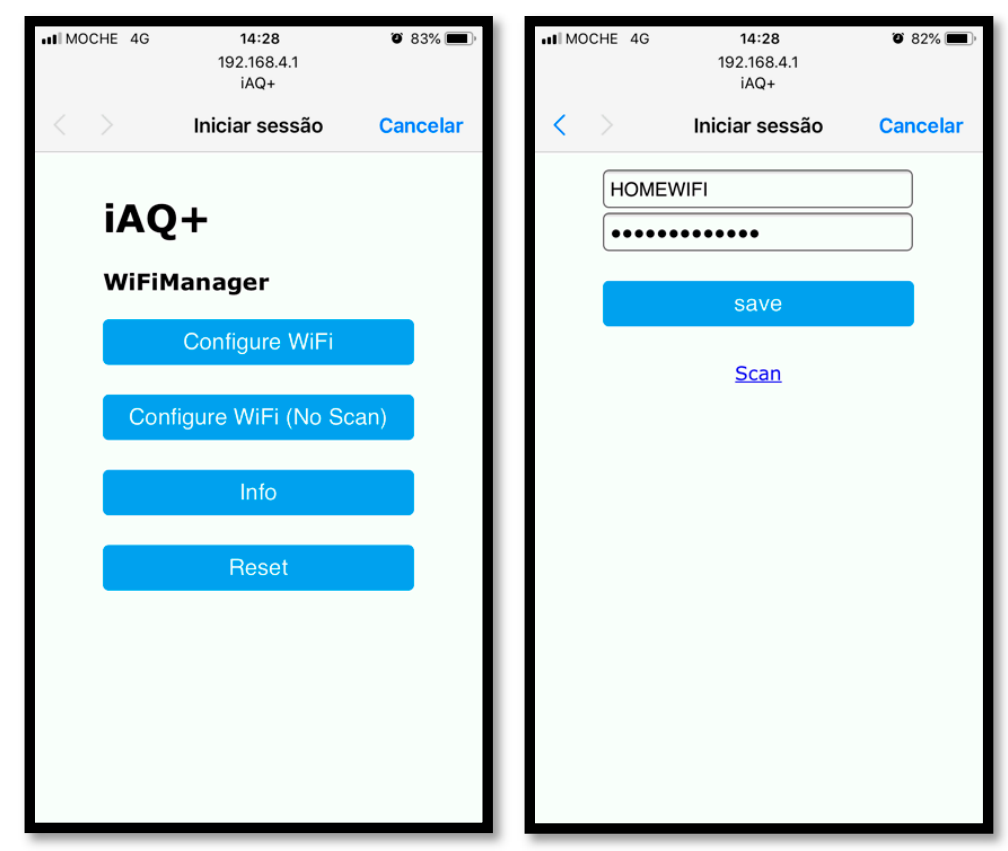

Figure 10. Wi-Fi configuration.

In this way, the $i A Q+$ can be easily installed by the end-user which not only follows the original paradigm of IoT solutions but also contributes to the low-cost aim of the presented solution.

Compared to several similar solutions proposed and described in Table 1, the $i A Q+$ supports push notifications to alert people in a timely way for enhanced living environments and occupational health by providing ventilation, deactivation of pollutant equipment and by activating air purification systems. When the parameters meet the setpoints for the correspondent working mode, the user is alerted to ensure a productive environment for teaching or correct laboratory environmental parameters. The $i A Q+$ offers a work mode feature; the user can configure setpoints for laboratory mode and schoolroom mode. Using the $i A Q+M o b i l e$, the user can easily change the work mode in real-time.

On one hand, compared to other systems proposed by References $[46,47,49,50]$ based on WSN, the $i A Q+$ provides several advantages in scalability and installation in indoor living environments as it is only necessary to configure the Wi-Fi Internet connection and it is not required to configure the sensor nodes and coordinators. On the other hand, compared to the other systems proposed by References [46,50-52] which do not use mobile computing, the $i A Q+$ provides smartphone and Web compatibility for data access. The solution proposed by Reference [48] supports mobile access. 
However, the proposed mobile app allows only to access the last collected data and does not support historical data access. The $i A Q+M o b i l e$ supports graphical presentation for an easy overview of the IEQ data by the end-user.

The IoT design facilitates the scalability of the proposed solution offering flexibility and expandability as the area can be monitored using only one $i A Q+$ unity, but other unities can be added if needed.

Enhancements to the system hardware and software are scheduled in order to incorporate other IEQ parameters such as noise supervision and/or experiment variables. So, as future work improvements and adaptions for specific laboratory tests, such as thermographic experiments applied to wood and trees are planned. The proposed solution has multiple benefits in installation and configuration as the $i A Q+$ incorporates wireless communication technology for data transmission, but also provides compatibility with both the standard domestic homes and smart homes.

Apache Kafka is an open-source stream-processing software platform for distributed high-throughput systems. This platform provides low-latency, built-in partitioning, replication and inherent fault-tolerance for real-time data handling. Apache Spark is a framework for large-scale data processing which can be used with Kafka to stream the data to solve the response time and system throughput problems. The SQL Server response time and system throughput tests were not performed. However, these evaluations are planned by the authors as long as the study of the incorporation of open-source platforms such as Apache Kafka and Apache Spark to face response time and system throughput difficulties.

It is imperative to enhance the IEQ conditions, and the authors consider that the first step is to implement real-time supervision to identify its variation and to plan interventions for enhanced living environments.

\section{Managerial Implication}

Regarding managerial implications, the results provide insights for enhanced living environments and laboratory experiments. In most university establishments, laboratories are also used as classrooms. Therefore, $i A Q+$ is relevant to provide a healthful and productive living environment but also to support experimental activities. LEC has a direct impact on test results and on the accuracy and consistency of test data that are affected by environmental conditions. Thus, the proposed solution offers an integrated management system for historical data analysis in order to guarantee the integrity of test results. The two functional modes of the $i A Q+$ solution, the laboratory mode and the schoolroom mode allow the user to configure setpoints for both modes. This will allow switching the functional mode in an agile way, contributing to increasing the quality of the laboratory experiments and teaching activities. The $i A Q+$ easy installation feature follows the original paradigm of IoT solutions and contributes to the low cost of the proposed solution. Most importantly, the real-time alerts promote behaviour changes to support the occupants to act promptly in order to provide a healthy and productive workplace for learning and a regulated environment for laboratory activities. The proposed solution provides a mobile application and a Web portal for IAQ data analytics which facilitates data access and analysis.

\section{Conclusions}

This paper presented an IoT real-time supervision system architecture named $i A Q+$ composed by a hardware prototype for data acquisition along with Web and mobile compatibility for data access. The proposed system provides temperature, relative humidity, barometric pressure and qualitative air quality supervision for both school and laboratory scenarios.

With the proliferation of IoT technologies, there is great potential to create automatic IEQ supervision solutions for enhanced living environments and occupational health.

The results achieved are promising, indicating an important contribution to LEC supervision solutions based on IoT. Using $i A Q+$, the monitored data can be particularly valuable to analyse and 
store the laboratory activities' conditions to ensure that they are stable in the course of the experiments conducted, as they influence the quality of the results.

Compared to existing systems, the $i A Q+$ supports push notifications to alert people in a timely way for enhanced living environments and occupational health; in addition, by supporting a work mode feature, the user can configure setpoints for laboratory mode and schoolroom mode. This system offers flexibility and expandability as the user can start with only one $i A Q+$ unity and add more unities if needed. However, quality assurance (QA) and quality control (QC) testing of the proposed study and the SQL Server response time and system throughput analysis was not done by the authors. In the future, the QA/QC should be implemented for enhanced product quality traceability and these response time and systems throughput evaluations will be conducted. The authors have also planned software and hardware improvements to adapt the system to specific laboratory tests, such as thermographic experiments applied to wood and trees. In spite of the influence of indoor environments in daily human activities, systems like this will contribute to ensuring a productive environment for teaching and proper LEC.

Author Contributions: G.M. and R.P. designed the study, developed the methodology, performed the analysis, and wrote the manuscript.

Funding: This research is framed in the project "TreeM-Advanced Monitoring \& Maintenance of Trees" N. ${ }^{\circ}$ 023831, 02/SAICT / 2016, co-financed by CENTRO 2020 and FCT, Portugal 2020 and structural funds UE-FEDER.

Acknowledgments: The financial support from the Research Unit for Inland Development of the Polytechnic Institute of Guarda is acknowledged.

Conflicts of Interest: The authors declare no conflict of interest.

\section{References}

1. Vilcekova, S.; Meciarova, L.; Burdova, E.K.; Katunska, J.; Kosicanova, D.; Doroudiani, S. Indoor environmental quality of classrooms and occupants' comfort in a special education school in Slovak Republic. Build. Environ. 2017, 120, 29-40. [CrossRef]

2. Bruce, N.; Perez-Padilla, R.; Albalak, R. Indoor air pollution in developing countries: A major environmental and public health challenge. Bull. World Health Organ. 2000, 78, 1078-1092. [PubMed]

3. Seguel, J.M.; Merrill, R.; Seguel, D.; Campagna, A.C. Indoor Air Quality. Am. J. Lifestyle Med. 2016, 11, 284-295. [CrossRef] [PubMed]

4. De Gennaro, G.; Dambruoso, P.R.; Loiotile, A.D.; Di Gilio, A.; Giungato, P.; Tutino, M.; Marzocca, A.; Mazzone, A.; Palmisani, J.; Porcelli, F. Indoor air quality in schools. Environ. Chem. Lett. 2014, 12, 467-482. [CrossRef]

5. Madureira, J.; Paciência, I.; Rufo, J.; Ramos, E.; Barros, H.; Teixeira, J.P.; de Oliveira Fernandes, E. Indoor air quality in schools and its relationship with children's respiratory symptoms. Atmos. Environ. 2015, 118, 145-156. [CrossRef]

6. Rupp, R.F.; Vásquez, N.G.; Lamberts, R. A review of human thermal comfort in the built environment. Energy Build. 2015, 105, 178-205. [CrossRef]

7. Giusto, D.; Iera, A.; Morabito, G.; Atzori, L. (Eds.) The Internet of Things: 20th Tyrrhenian Workshop on Digital Communications; Springer: New York, NY, USA, 2010; ISBN 978-1-4419-1673-0.

8. Gubbi, J.; Buyya, R.; Marusic, S.; Palaniswami, M. Internet of Things (IoT): A vision, architectural elements, and future directions. Future Gener. Comput. Syst. 2013, 29, 1645-1660. [CrossRef]

9. Ibaseta, D.; Molleda, J.; Díez, F.; Granda, J.C. Indoor Air Quality Monitoring Sensor for the Web of Things. Proceedings 2018, 2, 1466. [CrossRef]

10. Yin, Y.; Zeng, Y.; Chen, X.; Fan, Y. The internet of things in healthcare: An overview. J. Ind. Inf. Integr. 2016, 1, 3-13. [CrossRef]

11. Bhatt, Y.; Bhatt, C. Internet of Things in HealthCare. In Internet of Things and Big Data Technologies for Next Generation Healthcare; Bhatt, C., Dey, N., Ashour, A.S., Eds.; Springer International Publishing: Cham, Switzerland, 2017; Volume 23, pp. 13-33. ISBN 978-3-319-49735-8. 
12. Marques, G.; Pitarma, R. An indoor monitoring system for ambient assisted living based on internet of things architecture. Int. J. Environ. Res. Public Health 2016, 13, 1152. [CrossRef]

13. United Nations. World Population Ageing, 1950-2050; Department of Economic and Social Affairs, Population Division, United Nations: New York, NY, USA, 2002; pp. 11-13. ISBN 92-1-051092-5.

14. Centers for Disease Control and Prevention. The state of aging and health in America 2007. N. A. on an Aging Society. 2007. Available online: http://https:/ /www.cdc.gov/aging/pdf/saha_2007.pdf (accessed on 1 December 2018).

15. Koleva, P.; Tonchev, K.; Balabanov, G.; Manolova, A.; Poulkov, V. Challenges in designing and implementation of an effective Ambient Assisted Living system. In Proceedings of the 2015 12th International Conference on Telecommunication in Modern Satellite, Cable and Broadcasting Services (TELSIKS), Niš, Serbia, 14-17 October 2015; pp. 305-308.

16. Atzori, L.; Iera, A.; Morabito, G. The Internet of Things: A survey. Comput. Netw. 2010, 54, $2787-2805$. [CrossRef]

17. Caragliu, A.; Del Bo, C.; Nijkamp, P. Smart Cities in Europe. J. Urban Technol. 2011, 18, 65-82. [CrossRef]

18. Chourabi, H.; Nam, T.; Walker, S.; Gil-Garcia, J.R.; Mellouli, S.; Nahon, K.; Pardo, T.A.; Scholl, H.J. Understanding Smart Cities: An Integrative Framework. In Proceedings of the 2012 45th Hawaii International Conference on System Sciences, Maui, HI, USA, 4-7 January 2012; pp. 2289-2297.

19. Zanella, A.; Bui, N.; Castellani, A.; Vangelista, L.; Zorzi, M. Internet of Things for Smart Cities. IEEE Internet Things J. 2014, 1, 22-32. [CrossRef]

20. Hernández-Muñoz, J.M.; Vercher, J.B.; Muñoz, L.; Galache, J.A.; Presser, M.; Hernández Gómez, L.A.; Pettersson, J. Smart Cities at the Forefront of the Future Internet. In The Future Internet; Domingue, J., Galis, A., Gavras, A., Zahariadis, T., Lambert, D., Cleary, F., Daras, P., Krco, S., Müller, H., Li, M.-S., et al., Eds.; Springer Berlin Heidelberg: Berlin/Heidelberg, Germany, 2011; Volume 6656, pp. 447-462, ISBN 978-3-642-20897-3.

21. Skouby, K.E.; Lynggaard, P. Smart home and smart city solutions enabled by 5G, IoT, AAI and CoT services. In Proceedings of the 2014 International Conference on Contemporary Computing and Informatics (IC3I), Mysore, India, 14-17 December 2014; pp. 874-878.

22. Alaa, M.; Zaidan, A.A.; Zaidan, B.B.; Talal, M.; Kiah, M.L.M. A review of smart home applications based on Internet of Things. J. Netw. Comput. Appl. 2017, 97, 48-65. [CrossRef]

23. Theoharidou, M.; Tsalis, N.; Gritzalis, D. Smart Home Solutions: Privacy Issues. In Handbook of Smart Homes, Health Care and Well-Being; Van Hoof, J., Demiris, G., Wouters, E.J.M., Eds.; Springer International Publishing: Cham, Switzerland, 2017; pp. 67-81. ISBN 978-3-319-01582-8.

24. Feng, S.; Setoodeh, P.; Haykin, S. Smart Home: Cognitive Interactive People-Centric Internet of Things. IEEE Commun. Mag. 2017, 55, 34-39. [CrossRef]

25. Madureira, J.; Paciência, I.; Pereira, C.; Teixeira, J.P.; Fernandes, E.d.O. Indoor air quality in Portuguese schools: Levels and sources of pollutants. Indoor Air 2016, 26, 526-537. [CrossRef] [PubMed]

26. Stabile, L.; Dell'Isola, M.; Russi, A.; Massimo, A.; Buonanno, G. The effect of natural ventilation strategy on indoor air quality in schools. Sci. Total Environ. 2017, 595, 894-902. [CrossRef] [PubMed]

27. Kielb, C.; Lin, S.; Muscatiello, N.; Hord, W.; Rogers-Harrington, J.; Healy, J. Building-related health symptoms and classroom indoor air quality: A survey of school teachers in New York State. Indoor Air 2015, 25, 371-380. [CrossRef] [PubMed]

28. Choo, C.P.; Jalaludin, J. An overview of indoor air quality and its impact on respiratory health among Malaysian school-aged children. Rev. Environ. Health 2015, 30, 9-18. [CrossRef]

29. Lee, S.; Chang, M. Indoor and outdoor air quality investigation at schools in Hong Kong. Chemosphere 2000, 41, 109-113. [CrossRef]

30. Yang, L.; Yan, H.; Lam, J.C. Thermal comfort and building energy consumption implications-A review. Appl. Energy 2014, 115, 164-173. [CrossRef]

31. Havenith, G.; Holmér, I.; Parsons, K. Personal factors in thermal comfort assessment: Clothing properties and metabolic heat production. Energy Build. 2002, 34, 581-591. [CrossRef]

32. Pereira, L.D.; Cardoso, E.; da Silva, M.G. Indoor air quality audit and evaluation on thermal comfort in a school in Portugal. Indoor Built Environ. 2015, 24, 256-268. [CrossRef]

33. Srbinovska, M.; Gavrovski, C.; Dimcev, V.; Krkoleva, A.; Borozan, V. Environmental parameters monitoring in precision agriculture using wireless sensor networks. J. Clean. Prod. 2015, 88, 297-307. [CrossRef] 
34. Sanchez-Rosario, F.; Sanchez-Rodriguez, D.; Alonso-Hernandez, J.B.; Travieso-Gonzalez, C.M.; Alonso-Gonzalez, I.; Ley-Bosch, C.; Ramirez-Casanas, C.; Quintana-Suarez, M.A. A low consumption real time environmental monitoring system for smart cities based on ZigBee wireless sensor network. In Proceedings of the 2015 International Wireless Communications and Mobile Computing Conference (IWCMC), Dubrovnik, Croatia, 24-28 August 2015; pp. 702-707.

35. Zhou, P.; Huang, G.; Zhang, L.; Tsang, K.-F. Wireless sensor network based monitoring system for a large-scale indoor space: Data process and supply air allocation optimization. Energy Build. 2015, 103, 365-374. [CrossRef]

36. Marques, G.; Pitarma, R. IAQ Evaluation Using an IoT CO2 Monitoring System for Enhanced Living Environments. In Trends and Advances in Information Systems and Technologies; Rocha, Á., Adeli, H., Reis, L.P., Costanzo, S., Eds.; Springer International Publishing: Cham, Switzerland, 2018; Volume 746, pp. 1169-1177. ISBN 978-3-319-77711-5.

37. Pitarma, R.; Marques, G.; Ferreira, B.R. Monitoring Indoor Air Quality for Enhanced Occupational Health. J. Med Syst. 2017, 41, 23. [CrossRef]

38. Pitarma, R.; Marques, G.; Caetano, F. Monitoring Indoor Air Quality to Improve Occupational Health. In New Advances in Information Systems and Technologies; Rocha, Á., Correia, A.M., Adeli, H., Reis, L.P., Mendonça Teixeira, M., Eds.; Springer International Publishing: Cham, Switzerland, 2016; Volume 445, pp. 13-21. ISBN 978-3-319-31306-1.

39. Marques, G.; Pitarma, R. Smartwatch-Based Application for Enhanced Healthy Lifestyle in Indoor Environments. In Computational Intelligence in Information Systems; Omar, S., Haji Suhaili, W.S., Phon-Amnuaisuk, S., Eds.; Springer International Publishing: Cham, Switzerland, 2019; Volume 888, pp. 168-177. ISBN 978-3-030-03301-9.

40. Marques, G.; Pitarma, R. Using IoT and Social Networks for Enhanced Healthy Practices in Buildings. In Information Systems and Technologies to Support Learning; Rocha, Á., Serrhini, M., Eds.; Springer International Publishing: Cham, Switzerland, 2019; Volume 111, pp. 424-432. ISBN 978-3-030-03576-1.

41. Marques, G.; Pitarma, R. Monitoring Health Factors in Indoor Living Environments Using Internet of Things. In Recent Advances in Information Systems and Technologies; Rocha, Á., Correia, A.M., Adeli, H., Reis, L.P., Costanzo, S., Eds.; Springer International Publishing: Cham, Switzerland, 2017; Volume 570, pp. $785-794$. ISBN 978-3-319-56537-8.

42. Marques, G.; Roque Ferreira, C.; Pitarma, R. A System Based on the Internet of Things for Real-Time Particle Monitoring in Buildings. Int. J. Environ. Res. Public Health 2018, 15, 821. [CrossRef]

43. Akkaya, K.; Guvenc, I.; Aygun, R.; Pala, N.; Kadri, A. IoT-based occupancy monitoring techniques for energy-efficient smart buildings. In Proceedings of the 2015 IEEE Wireless Communications and Networking Conference Workshops (WCNCW), New Orleans, LA, USA, 9-12 March 2015; pp. 58-63.

44. Wargocki, P.; Wyon, D.P.; Sundell, J.; Clausen, G.; Fanger, P.O. The Effects of Outdoor Air Supply Rate in an Office on Perceived Air Quality, Sick Building Syndrome (SBS) Symptoms and Productivity. Indoor Air 2000, 10, 222-236. [CrossRef]

45. Srivatsa, P.; Pandhare, A. Indoor Air Quality: IoT Solution. In Proceedings of the National Conference NCPCI, 19 March 2016; Volume 2016, p. 19.

46. Salamone, F.; Belussi, L.; Danza, L.; Galanos, T.; Ghellere, M.; Meroni, I. Design and Development of a Nearable Wireless System to Control Indoor Air Quality and Indoor Lighting Quality. Sensors 2017, $17,1021$. [CrossRef]

47. Bhattacharya, S.; Sridevi, S.; Pitchiah, R. Indoor air quality monitoring using wireless sensor network. In Proceedings of the 2012 Sixth International Conference on Sensing Technology (ICST), Kolkata, India, 18-21 December 2012; pp. 422-427.

48. Salamone, F.; Belussi, L.; Danza, L.; Ghellere, M.; Meroni, I. Design and Development of nEMoS, an All-in-One, Low-Cost, Web-Connected and 3D-Printed Device for Environmental Analysis. Sensors 2015, 15, 13012-13027. [CrossRef]

49. Wang, S.K.; Chew, S.P.; Jusoh, M.T.; Khairunissa, A.; Leong, K.Y.; Azid, A.A. WSN based indoor air quality monitoring in classrooms. AIP Conf. Proc. 2017, 1808, 020063.

50. Liu, J.; Chen, Y.; Lin, T.; Lai, D.; Wen, T.; Sun, C.; Juang, J.; Jiang, J.-A. Developed urban air quality monitoring system based on wireless sensor networks. In Proceedings of the 2011 Fifth International Conference on Sensing Technology, Palmerston North, New Zealand, 28 November-1 December 2011; pp. 549-554. 
51. Kang, J.; Hwang, K.-I. A Comprehensive Real-Time Indoor Air-Quality Level Indicator. Sustainability 2016, 8, 881. [CrossRef]

52. Benammar, M.; Abdaoui, A.; Ahmad, S.; Touati, F.; Kadri, A. A Modular IoT Platform for Real-Time Indoor Air Quality Monitoring. Sensors 2018, 18, 581. [CrossRef] [PubMed]

53. Klein, R.C.; King, C.; Kosior, A. Laboratory air quality and room ventilation rates: An update. J. Chem. Health Saf. 2011, 18, 21-24. [CrossRef]

54. Stuart, R.; Sweet, E.; Batchelder, A. Assessing general ventilation effectiveness in the laboratory. J. Chem. Health Saf. 2015, 22, 2-7. [CrossRef]

55. Yau, Y.H.; Chew, B.T.; Saifullah, A.Z.A. Studies on the indoor air quality of Pharmaceutical Laboratories in Malaysia. Int. J. Sustain. Built Environ. 2012, 1, 110-124. [CrossRef]

56. Ugranli, T.; Gungormus, E.; Sofuoglu, A.; Sofuoglu, S.C. Indoor Air Quality in Chemical Laboratories. In Comprehensive Analytical Chemistry; Elsevier: Amsterdam, The Netherlands, 2016; Volume 73, pp. 859-878. ISBN 978-0-444-63605-8.

57. Morbeck, D.E. Air quality in the assisted reproduction laboratory: A mini-review. J. Assist. Reprod. Genet. 2015, 32, 1019-1024. [CrossRef]

(C) 2019 by the authors. Licensee MDPI, Basel, Switzerland. This article is an open access article distributed under the terms and conditions of the Creative Commons Attribution (CC BY) license (http:/ / creativecommons.org/licenses/by/4.0/). 